\title{
.
}

\section{AS ARTES VISUAIS COMO CAMPO DE CONHECIMENTO NO PROJETO ARTE NA ESCOLA - DAC/UFSC}

Originais recebidos em: 26/05/2010

Aceito para publicação em: 18/08/2011

Richard Perassi Luiz de Sousa Universidade Federal de Santa Catarina riperassi@ig.com.br

\section{Resumo}

Este texto apresenta e justifica o conteúdo trabalhado no curso de extensão "As Artes Visuais como campo de conhecimento", que foi promovido pelo Departamento Artístico Cultural - DAC/UFSC, dentro do projeto "Arte na Escola". O curso foi dirigido a professores de Arte e também recebeu outros interessados no estudo de Artes Visuais com foco na produção contemporânea. A arte se justifica como campo de conhecimento, visto que, ao longo de sua história, foram desenvolvidos muitos saberes, tecnologias e conhecimentos aplicados ao desenvolvimento das atividades artísticas. Além disso, cada obra de arte única e inovadora representa um testemunho de seu tempo e oferece um novo conjunto de conhecimentos que amplia o acervo cultural da humanidade. Por fim, os conhecimentos e os produtos artísticos são também aplicados no desenvolvimento de outras áreas do conhecimento.
Palavras-chave: Conhecimento - Arte. Ensino de Arte. História da Arte.

\section{VISUAL ARTS AS THE FIELD OF KNOWLEDGE IN ARTE NA ESCOLA - DAC/UFSC PROJECT}

\begin{abstract}
This paper presents and justifies the content worked in the extension course "The Visual Arts as a field of knowledge," which was sponsored by the Departamento Artístico Cultural - DAC/ UFSC, within the project "Arte na Escola". The course was directed at teachers of Art and also received other stakeholders in the study of Visual Arts, focusing on contemporary art. Art is justified as a field of knowledge in that, throughout its history, many have been developed knowledge, technologies and expertise applied to the development of artistic activities. In addition, each work of art represents a unique and innovative testimony of their time and offers a new set of knowledge, which broadens the cultural heritage of humanity. Finally, knowledge and artistic products are also applied in developing other areas of knowledge.
\end{abstract}

Keywords: Knowledge - Art. Art Education. Art History. 


\section{INTRODUÇÃO}

\subsection{Apresentação}

O curso "As Artes Visuais como campo de conhecimento" foi desenvolvido nas dependências do Departamento Artístico Cultural - DAC/UFSC, dentro do projeto "Arte na Escola", no período vespertino, às quartas-feiras, das 14 horas às 17 horas, durante todo o mês de abril e primeira quinzena do mês de maio do ano de 2008 .

O trabalho foi desenvolvido com base na obra "Roteiro Didático da Arte na Produção do Conhecimento" (PERASSI, 2005), cujo autor foi o ministrante do curso. O objetivo do trabalho consistiu em (1) relacionar teoricamente Arte e Conhecimento; (2) apresentar a relação entre Arte e Conhecimento no decorrer do percurso histórico ocidental; (3) descrever e enfatizar essa relação no contexto artístico contemporâneo.

O trabalho dirigido a professores de Arte atendeu, também, outros interessados em Artes Visuais contemporâneas. Para tanto, foram considerados os principais conceitos que fundamentam o estudo de Arte e, ainda, tratados o percurso das Artes Visuais relacionadas ao conhecimento desde a Pré-história, considerando mais especificamente a diferenciação das expressões estético-artística, ao longo da História Ocidental, com base em três estilos básicos: 1) Naturalista; 2) Idealista e 3) Expressivo. É possível perceber que, antes do período contemporâneo, as Artes Visuais, especialmente a pintura, repetiram sazonalmente esses estilos, especialmente se considerarmos a centralidade histórico-ocidental dos estilos idealismo-simbólico na Arte Medieval, naturalismo-humanista no Renascimento e a expressividade teatral no período Barroco. Porém, os fenômenos de "desestetização" e "desmaterialização" das obras de arte contemporâneas indicaram a substituição dessa categorização estilística por categorias de linguagens artísticas tais como "assemblage", “instalação" e "performance", entre outras.

\subsection{Arte}

O termo "Arte" não representa uma única coisa porque indica muitas coisas diferentes entre si, como músicas, danças, peças teatrais, performances, quadros, esculturas, filmes, 
vídeos. Além disso, o que é indicado e percebido como arte em um dado momento pode não ser confirmado em outro.

A questão é difícil, porque o fenômeno artístico está em constante transformação, contradizendo definições e frustrando critérios de determinação do que seja o valor de uma obra de arte. Com alguma razão, há quem, como Dino Formaggio, considere que "Arte é tudo aquilo que os homens chamam de Arte" (LENARTOVICZ, 2009).

Mais frequente ainda são declarações de pessoas informando que jamais pensariam em atribuir a condição de obra de arte a certas coisas que são apresentadas por especialistas como obras de valor artístico.

Quanto mais recentes são as obras de arte, mais estranhas e indignas parecem ser diante da opinião pública não especializada. Por que grande parte das obras produzidas no momento contemporâneo causa estranhamento e decepção?

Muito antigamente, essas questões não eram relevantes, pelo menos para as pessoas comuns, porque as obras de arte eram sempre justificadas por uma aplicação prática, simbólica ou ritualística. A arte se expressava na produção de instrumentos utilitários ou servia para compor representações, ilustrações ou, ainda, poderia cumprir uma função mágico-religiosa, na realização de ritos e de objetos de magia ou de religião (FICHER, 1979; PERASSI, 2005).

Desde os tempos mais primitivos, Arte e Técnica são áreas e atividades conjugadas. O seu desenvolvimento comum acontece nas ações de produção ou nas atuações profissionais. Depois do período pré-histórico em que a Arte, a Ciência e a Religião eram praticadas em conjunto e de maneira quase indistinta, as atividades humanas foram sendo conceitualmente divididas entre teoria e prática (FICHER, 1979; PERASSI, 2005).

Filosofia e Ciência passaram a compor o campo da teoria. Técnica e Arte passaram a compor o campo da prática; portanto, as atividades práticas envolvendo aspectos artísticos e técnicos atualmente são percebidas como artísticas por alguns ou como artesanais por outros.

De qualquer maneira, até hoje, se alguém realiza uma atividade prática com maestria, por exemplo, faz um bolo ou um desenho, um truque com as mãos ou um drible gracioso num jogo de bola, essa pessoa é denominada artista. Assim, toda atividade prática exercida por mulheres e homens está inserida no mais amplo campo do que pode ser denominado de Arte.

$\mathrm{Na}$ Grécia Clássica, esse amplo campo da Arte foi um pouco reduzido, porque houve a distinção entre Arte e Técnica, sendo o poético ou artístico considerado como algo além da 
Técnica. Isso foi concebido pelo conceito de poiésis que, em grego, quer dizer criação, fabricação ou confecção. Em latim, o mesmo termo foi adotado como poésis, para indicar a obra poética. O poético representa um fazer especial, que é criativo e intuitivo, reforçando que Arte é campo de um fazer, mas como uma prática especial decorrente da poesia (NEVES, 1986).

A poesia não está somente nos poemas, mas se expressa em todo fazer poético que supera a técnica pura e simples (DUARTE JR., 2001; JAKOBSON, 1977). Usando o exemplo anterior, recordando o ato de fazer um bolo, podemos dizer que a poesia é o "ingrediente" ou elemento que a receita não consegue definir. Assim, há pessoas que fazem um justo bolo de receita e outras que acrescentam poesia à técnica descrita na receita e, pela diferenciação de seu produto, passam a ser vistas como artistas.

O valor poético ou estético habilita o resultado de um fazer ou o produto de uma técnica, que passam a requerer a condição de obra de arte. Assim, Estética é campo que reúne, estuda e avalia todas as manifestações ou toda a produção poética. Por isso, o campo de estudos estéticos considera Arte um objeto de estudo muito especial.

O fato de expressar valor estético como um produto poético resultante de um fazer prático não garante, entretanto, que um objeto seja visto como obra de arte. Isso porque Arte é fenômeno social que, ao longo do tempo, foi sendo cada vez mais institucionalizado. Portanto, obra de arte é todo objeto ou fenômeno estético que é assim reconhecido pelo sistema social de institucionalização dos objetos artísticos (OLIVEIRA, 1998; PERASSI, 2008).

Ao longo da História, o sistema de institucionalização foi sendo composto por academias, galerias, museus, escolas e meios de comunicação. Além dos artistas, uma série de outros profissionais, como galeristas, críticos, jornalistas especializados ou não, curadores, teóricos e professores são habilitados pelo sistema para organizar o processo de inclusão dos objetos e dos fenômenos estéticos nos acervos artísticos da humanidade.

No decorrer de seu percurso histórico, os fazeres artísticos compuseram e organizaram a Arte como campo de conhecimento. Esse conhecimento é expresso nos materiais, nas técnicas, em todos os elementos das atividades artísticas e, especialmente, nas obras de arte. $\mathrm{O}$ estudo de Arte como campo de conhecimento ocorre também em outras áreas do saber como História, Filosofia e Comunicação, entre outras. Os processos, técnicas, linguagens e expressões que foram acumulados ao longo dos tempos constituíram um vasto acervo de conhecimentos, de processos e de objetos que compõem a cultura artística (PERASSI, 2005). 


\subsection{Obras de arte.}

As obras de arte materiais são coisas ou objetos artísticos tangíveis e relativamente permanentes no espaço e no tempo, como as pinturas, esculturas e fotografias sobre suportes físicos permanentes, além de infografias impressas, instalações, interferências físicas, entre outras. As apresentações musicais, teatrais e outras performances compõem o conjunto de expressões artísticas performáticas, intangíveis e recorrentes, que acontecem necessariamente no tempo, apesar de suas execuções ou atuações ocuparem temporariamente o espaço. Ao encerrar uma performance, é preciso recomeçar a atuação para que a arte aconteça novamente, enquanto as esculturas ou pinturas permanecem existindo e, uma vez expostas, continuam agindo ou atuando.

O que define um objeto ou uma atuação como artísticos é o seu reconhecimento como obra de arte. O reconhecimento de algo como estético ou apreciativo é determinado pelo receptor em geral que percebe alguma coisa como objeto ou evento estético (MUKARÖVSKÝ, 1988). O que pode reconhecer um objeto ou fenômeno como obra de arte é o sistema de institucionalização, que valida e institui a obra nos acervos da cultura como manifestação relevante (OLIVEIRA, 1998; PERASSI, 2008).

Nos objetos ou fenômenos estéticos que, às vezes, são incrementados com aspectos lúdicos, a função estética predomina sobre as outras funções, como as práticas, as teóricas ou as mágico-religiosas (MUKARÖVSKÝ, 1988). Isso indica que o objeto ou evento se presta a ser reconhecido como obra de arte. Com a ampliação da função estética na obra de arte como função expressiva ou apreciativa, a dimensão artística foi transformada, relacionando os estímulos percebidos com todas as respostas afetivas e não somente com o sentimento de beleza. Até o ato de se negar à emoção ou à fruição também é considerado uma atitude estética. Por comparação, isso se justifica da mesma maneira que o ato de ficar imóvel, sem tomar uma atitude, ser igualmente percebido como uma questão de atitude.

Houve, portanto, a quebra do vínculo entre Arte e beleza. "Beleza é nome de qualquer coisa que não existe, que dou às coisas em troca do agrado que me dão", essa frase foi escrita por Fernando Pessoa, sob o heterônimo de Alberto Caeiro (DUARTE, JR., 2001). A base da citação anterior é o conceito de beleza de São Tomás de Aquino (1225-1274), indicando que “o belo é aquilo que agrada à visão", que pode ser reduzido para "o belo é aquilo que agrada" 
ou ampliado para "o belo é aquilo que agrada aos sentidos em geral". Atualmente, a atribuição de obra de arte pode ser dada a quaisquer objetos ou atuações em troca de qualquer interesse ou desinteresse que possam suscitar, desde que provoquem uma atitude diferente das atitudes práticas, teóricas ou mágico-religiosas, entre outras possibilidades.

Há uma diferenciação entre o interesse estético ou artístico suscitado pela obra de arte e os outros interesses ou finalidades, sejam estas práticas, teóricas ou mágico-religiosas. Isso demarca que a disposição em Arte, por meio das atividades artísticas ou das obras de arte, quando está a serviço de outras funções não estéticas, caracteriza um fenômeno diferente daquele puramente artístico. Trata-se de um outro fenômeno que é denominado "arteaplicada" (LUCIE-SMITH, 1990). Assim, temos a arte aplicada à educação, à moda, à comunicação e ao design, entre outras possibilidades.

O contexto e a situação podem indicar um objeto ou fenômeno como uma obra de arte ou de arte aplicada. A mesma obra em situações diferentes recebe conceituações também diferenciadas. Por exemplo, um cartaz cuja mensagem está vencida, porque já ocorreu o evento nele anunciado, quando é reapresentado como objeto estético, pode ser percebido como obra de arte. O mesmo acontece com objetos artesanais. A produção artesanal é igualmente artística, porém, o ambiente comercial que expõe seus produtos como objetos de uso ou de decoração corrompe seu caráter puramente apreciativo, sobrepondo outras funções à questão estética.

Há um exemplo singelo, mas muito didático, para considerarmos o valor estético de uma obra. Assim, uma pintura é um retrato quando nos interessamos pela pessoa retratada. Por outro lado, a mesma pintura é percebida prioritariamente por seu valor estético, quando nos interessamos pela obra e não necessariamente pelo modelo. Um retrato é candidato a ser obra de arte, quando temos desejo ou necessidade estética de adquiri-lo, mesmo sem saber quem é a pessoa retratada.

\subsection{Arte contemporânea.}

Contemporâneo quer dizer "ao mesmo tempo". O termo indica, portanto, aquilo que acontece juntamente com alguma outra coisa. Em se tratando de Arte, muitos fatos e eventos aconteceram e acontecem simultaneamente, mas denomina-se contemporâneo o período que se seguiu à Segunda Guerra Mundial, estabelecendo um novo nome ou novo rótulo para 
indicar o acervo dos produtos artísticos que alteraram ou sobrepujaram as obras do período modernista (PERASSI, 2005).

São constantemente necessários nomes novos para designar coisas novas. O que renovou a concepção artístico-modernista passou a ser denominado contemporâneo ou pósmodernista (PERASSI, 2005). A História não consegue apreender imediatamente o novo, porque necessita de algum distanciamento para compreender os fenômenos que estuda. Por isso, durante a segunda metade do século XX, os cursos de História da Arte foram muito evasivos com relação à Arte Contemporânea. Um fenômeno que era pouco compreendido e, portanto, difícil de ser explicado.

Em síntese, tudo o que é produzido neste período em que vivemos, de algum modo, nos é contemporâneo. Todavia, o que é considerado "Arte Contemporânea" não só deve ter sido produzido nos últimos cinquenta anos, mas também deve, de algum modo, diferenciar-se das produções anteriores. Tudo o que é produzido enquanto vivemos nos é contemporâneo, mas nem todas as obras desse período expressam as características do que foi denominado Arte Contemporânea.

Por outro lado, à medida que foram sendo identificadas as características de Arte Contemporânea, outros movimentos e manifestações, anteriores ao final da Segunda Guerra Mundial, foram sendo recuperados como precursores do contemporâneo. Entre esses, destacam-se os movimentos Surrealista e Dadaísta e, especialmente, a obra de Marcel Duchamp, indicando que as raízes do contemporâneo foram plantadas por fatos, objetos e eventos ainda no período de consolidação do Modernismo. Esses acontecimentos negaram o Racionalismo, o Formalismo geométrico e o Funcionalismo, que caracterizaram a fase áurea do Modernismo (PERASSI, 2005).

Um conjunto de expressões dentro do Modernismo caracterizou a "antiarte", com obras que, ao mesmo tempo em que manifestavam um caráter artístico, desafiavam os preceitos anteriores sobre a natureza do fenômeno Arte. O Dadaísmo foi o primeiro movimento antiarte (LUCIE-SMITH, 1990).

O que foi contestado não foi apenas a beleza, como a única finalidade artística, porque isso já fora consolidado desde o Romantismo, com a indicação, entre outros, do feio e do grotesco como valores estéticos. Além disso, posteriormente, foram negadas as próprias emoções, que eram tão necessárias aos românticos. 
Primeiramente, ocorreu o processo "desestetização" da obra de arte, porque as obras de arte foram suprimindo seu apelo estético afirmativo, deixando de promover o fenômeno emocional e tornando-se cada vez mais cerebral. Depois houve a "desmaterialização" da obra de arte, em que seu aspecto material deixou de expressar diretamente um conteúdo afetivo. $\mathrm{O}$ conteúdo da obra conceitual, por exemplo, deve ser atingido por interações simbólicas, de acordo com as significações atribuídas aos materiais e aos elementos da composição (FABRINI, 2002).

Houve, ainda, a "hibridização" e a "virtualização" dos produtos artísticos, rompendo com as categorias artísticas tradicionais, como dança, música, teatro, pintura e escultura, entre outras. Hoje são comuns categorias híbridas, como assemblage, dança-teatro, videoinstalação e infogravura, entre outras. Além disso, a produção digital ou digitalização de dados sonoros e visuais inseriu a produção artística nos ambientes virtuais, multimidiáticos e interligados à Internet ou Rede Mundial de Computadores (LUCIE-SMITH, 1990; PERASSI, 2005).

Tudo isso retirou das obras de arte os padrões acadêmicos, que foram vigentes por cerca de quinhentos anos, ocupando o período de tempo entre Renascimento e Impressionismo. Primeiramente, Arte Modernista e, posteriormente, Arte Contemporânea recuperaram milhares de anos de Arte, retrocedendo até a Pré-história; mas também projetaram Arte para o futuro, considerando inicialmente a Revolução Industrial, com suas consequências e depois a Revolução Digital e suas implicações.

A educação artístico-acadêmica que ainda está em nós provoca um estranhamento frente às obras ditas contemporâneas. Diante dessas obras, buscamos a beleza e não a encontramos, buscamos as emoções e, também, não as encontramos. Insistimos em querer admirar suas formas ou suas sequências de eventos, mas seu sentido é conceitual, não sendo normalmente apreendido por uma experiência direta de percepção, porque requer a mediação intelectual e o conhecimento.

Sem experimentar, sem refletir, sem aprender não é possível aceitar e tão pouco gostar da produção artística atual. Por isso, a necessidade constante de Educação Estética, de estudos de Sociologia e de História Crítica da Arte. O fenômeno artístico deve ser tratado de maneira interativa no seu contexto sociocultural de emergência, contemplando inclusive os aspectos políticos e econômicos dessa relação.

A estética modernista foi imposta na vida da população global por meio da produção industrial e da cultura de massa. Ninguém se assusta ou discute sobre um tecido estampado 
com motivos abstratos e coloridos de Wassily Kandinsky (1866-1944) ou Joan Miró (18931983). As mesmas pessoas que se irritam ao ver quadros abstratos em uma exposição de Arte, porque não podem lhes atribuir significação, consomem seus motivos estampados e legitimados em mercadorias, como roupas e toalhas de mesa e de banho. A condição de arte aplicada à mercadoria atribuiu plena significação às expressões abstratas.

O contemporâneo também nos é imposto todos os dias, através dos meios de comunicação de massa ou de segmentação. Muitas vezes, nós o consumimos sem crítica, sem análise, sem comparação. As questões contemporâneas tratadas com Arte não pertencem unicamente à esfera artística. São as mesmas que ocupam "os corações e as mentes" da sociedade como um todo. Assim, temas sobre o mercado, a mídia, a ecologia, o terrorismo e a guerra, entre outros, estão presentes em Arte e nos altos debates políticos e filosóficos, aparecendo, também, na imprensa e nas conversas corriqueiras de nosso dia a dia.

De acordo com os registros do atentado do dia 11 de setembro de 2001, disponíveis no sítio de comunicação digital ClicRBS, logo depois da destruição das Torres Gêmeas do World Trade Center, às 18 horas e 10 minutos, "o então prefeito de Nova York, Rudolf Giulani, concedeu entrevista coletiva e pediu para os nova-iorquinos ficarem em casa no dia seguinte", para facilitar a ação das equipes de trabalho. No dia 03 de outubro de 2001, o presidente dos Estados Unidos, George Bush, pediu aos norte-americanos para seguirem seu exemplo e saírem de casa para gastar dinheiro, mantendo a economia dos Estados Unidos em alta.

Muitos aspectos da contemporaneidade são ressaltados em todas as esferas da cultura de nosso tempo; entretanto, é o consumo e o mercado que determinam e caracterizam a dinâmica econômica da atualidade, influenciando diretamente áreas como Política, Moral e Cultura.

Em primeira instância, a vanguarda em Arte se contrapõe aos valores culturais já estabelecidos, rompendo com a tradição e indicando o que há de novo no ambiente social. $\mathrm{O}$ que a Arte inovadora expressa geralmente já existe, mas essa existência não foi ainda revelada por outros meios de representação. Nesse sentido, os artistas são considerados "antenas parabólicas do mundo", porque metaforicamente compõem parábolas ou representações que expressam na terra as coisas que ainda estão no ar.

As manifestações artísticas de vanguarda, em seguida, passam também a compor o acervo cultural, como parte de uma tradição artística continuada. As obras são incorporadas pela cultura e, deixando de ser novidade, atuam como documentos históricos, como registros 
estéticos e como textos culturais. No campo da cultura de consumo ou de mercado, as manifestações contestadoras são posteriormente incorporadas como mercadorias. Assim, surgiram os objetos de consumo para os atuais "Hippies de butique" ou para os "Punks de gel perfumado" e, ainda, para outras "tribos" pseudocontestadoras que circulam nos ambientes dos shopping centers.

A Arte prossegue revelando, contestando, aderindo, confundindo, mas seu destino não é sempre heroico, não é sempre valoroso, não atende a uma finalidade gloriosa e prédeterminada, como foi proposto por alguns de seus defensores, em diversos momentos históricos. A necessidade de Arte no campo da cultura e do conhecimento decorre de sua natureza sintomática, porque as obras de arte são sintomas sociais. Por isso, essas obras despertam o interesse de estudiosos em diversas áreas do conhecimento.

Do ponto de vista subjetivo, Arte é campo de expressão e vivência afetiva, o que interessa ao público, aos colecionadores e aos estetas. No contexto da comunicação políticosocial, Arte torna públicas as ideias que ajudam a compor ideologias, o que interessa ao público, aos políticos e aos publicitários. No campo comercial, Arte oferece mercadorias e promove modismos, o que interessa ao público, aos comerciantes e aos investidores. No âmbito dos estudos socioculturais, Arte é sintomática, expressando diretamente ou por metáforas o ambiente social e, especialmente por isso, interessa a todos nós.

\subsection{Arte e Conhecimento.}

A relação entre Arte e Conhecimento é estabelecida por diversos liames. Entre esses, há os que entrelaçam Arte e Técnica, promovendo o desenvolvimento de conhecimentos técnicos e tecnológicos, a partir das necessidades de expressão artística. Esses conhecimentos, primeiramente, são produzidos nas áreas artísticas. Mas, posteriormente, participam do desenvolvimento de outras áreas de aplicação. Do mesmo modo, os conhecimentos técnicos e tecnológicos de outras áreas muito diversificadas são descobertos e aplicados à produção artística. Arte é campo de reciclagem de objetos, ferramentas, produtos, práticas e técnicas para atender suas finalidades poético-criativas.

A utilização por outras áreas dos conhecimentos técnicos e tecnológicos oriundos das áreas artísticas ou o aproveitamento artístico de técnicas e de tecnologias de outras áreas implica novos conhecimentos, que são decorrentes da mudança do contexto de utilização das técnicas ou das tecnologias (FICHER, 1979; PERASSI, 2005). Um exemplo é o pixel digital 
dos computadores, quando considerado como herdeiro do ponto gráfico e, também, da técnica pontilhista do movimento Neo-Impressionista e dos mosaicos bizantinos.

As linguagens e os processos de comunicação estão inclusos no câmbio tecnológico, como uma dupla via entre áreas artísticas e outras áreas do conhecimento e da produção. Assim, o cartaz é herdeiro da pintura e da estamparia, enquanto a videoarte descende da televisão, entre muitos outros exemplos possíveis. Atualmente, a tecnologia digital reuniu em uma mesma matriz inúmeras linguagens e processos artísticos que são aplicados em diversos produtos de comunicação, seja essa comunicação interpessoal, institucional ou comercial.

No campo estético-artístico mais específico, que se dedica à expressão dos sentimentos e intenções, com base na definição de estilos pessoais ou sociais, Arte é campo de autoconhecimento, seja ele individual ou social. Os textos artísticos, assim como os outros textos, apresentam um caráter histórico, "pois cada período coloca para os homens certos problemas e os textos pronunciam-se sobre eles" (PLATÃO; FIORIN, 2006). Do ponto de vista estético, há informações e conhecimentos expressos e percebidos na organização ou composição pré-denotativa da matéria expressivo-constitutiva da mensagem artística.

Exemplos do conteúdo estético como campo do conhecimento são dados nas imagens a seguir (Figuras 1 e 2), pois, ambas apresentam o mesmo tema "Madona com criança", as mesmas figuras (mulher e criança) e utilizam recursos técnicos semelhantes, partindo de uma superfície pintada (técnica de pintura). Todavia, na primeira imagem, a tinta foi utilizada de maneira mais homogênea em muitas partes. As áreas coloridas revelam uma superfície plana ou são desenhadas para sugerir dobras, configurando formas com contornos rigidamente definidos. Assim, a mensagem visual se mostra mais plana, recortada ou geometricamente mais estilizada e antinaturalista ou idealista.

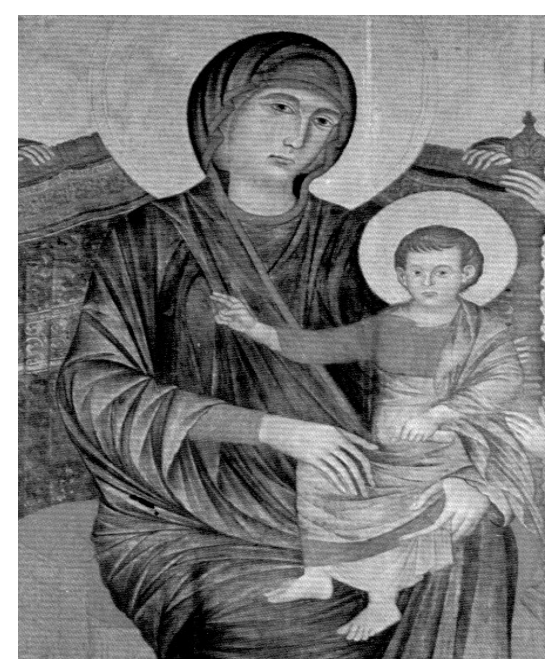


Figura 1: Madona com criança no trono (detalhe). Cimabue, final do séc. XIV

Fonte: Perassi (2005).

Na segunda imagem (Figura 2), a tinta foi matizada em diferentes tons, mesmo dentro das formas de fundo, e a separação entre as formas se estabelece com contornos menos rígidos, por isso, a mensagem visual esconde o plano do suporte, sugerindo volumes, e os contornos são mais dissimulados, propondo uma representação mais fotográfica ou naturalista.

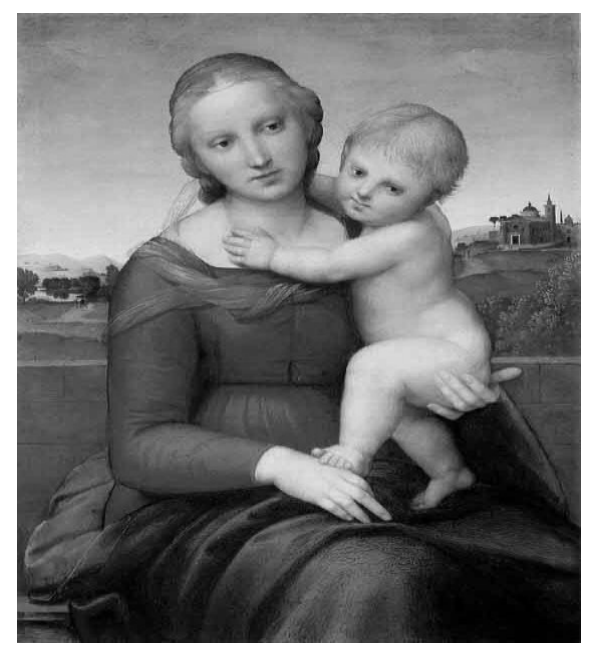

Figura 2: Madona e criança. Rafael Sanzio, séc. XVI Fonte: Perassi (2005).

No contexto de História da Arte, com mais de um século de diferença entre o momento de produção de cada obra, as duas emolduram o movimento artístico-pictórico renascentista. A primeira demarca os primeiros sinais da pintura renascentista, ainda marcada pela estética idealista medieval. A segunda apresenta a pintura renascentista prestes a ser transformada pelo Maneirismo, mas ainda bem marcada pela estética naturalista.

O movimento artístico-renascentista expressou em sua arte a influência filosófica do Humanismo ressurgente no período, como oposição ao pensamento predominantemente teocrático do período medieval. A temática figurativa das duas imagens enfoca "Maria" e "Menino Jesus", mas a comunicação pré-denotativa da linguagem estético-artística da segunda imagem (Figura 2) assinala o humanismo renascentista, por meio do tratamento 
naturalista de sua composição. Assim, a segunda imagem opõe-se ao estilo ainda predominantemente idealista da primeira imagem (Figura1). Por isso, a imagem pintada por Rafael (Figura 2) propõe um conhecimento humanista em oposição ao discurso idealistateocrático ainda resistente e predominante na obra de Cimabue (Figura 1).

Por variações expressivas como as apresentadas nas imagens anteriores, envolvendo técnicas e linguagens diferenciadas, o fenômeno Arte se mostra como objeto de estudo e campo de conhecimento porque, ao longo de sua história, houve uma extensa produção de conhecimentos diversificados e de diferentes métodos destinados ao desenvolvimento das atividades artísticas. As obras em si são igualmente objetos do conhecimento que, além do conteúdo denotativo, informam ainda sobre os sentimentos e os pensamentos de seu tempo, revelados nos modos de produção e tratamento de suas composições. Todos esses elementos teóricos, práticos e processuais, produzidos em função do desenvolvimento artístico, e o próprio conjunto de todas as obras de arte oferecem conhecimentos, que participam do acervo cultural da humanidade.

\section{MÉTODO E RELATO DAS AULAS}

O curso aconteceu no prédio da antiga igreja que, atualmente, compõe o conjunto de espaços culturais do DAC/UFSC. As aulas acorreram nas tardes de quarta-feira, com três horas-aula para cada um dos sete encontros, que foram promovidos durante o mês de abril e parte do mês de maio de 2008, somando 21 horas-aula de curso. Os recursos utilizados foram exposições orais, leituras de textos e apresentações de lâminas, por meio de projetor, a partir de arquivos do programa Power Point. Foram produzidos e reproduzidos um texto base e um conjunto de oitenta lâminas para as apresentações nas aulas.

A primeira parte do curso tratou das conceituações e do papel da Arte na produção do conhecimento e na prática pedagógica. A segunda parte tratou das relações entre Arte, Cultura e História, com maior exposição de imagens.

O conteúdo ministrado no curso, inclusive o texto especialmente produzido, foi baseado no livro escrito pelo ministrante. De fato, anteriormente, o próprio livro foi produzido para servir como material de apoio didático para professores de Arte do Ensino Médio. Do mesmo modo, outras edições do curso também foram anteriormente apresentadas para grupos de professores nas cidades de Campo Grande/MS e de Rio de Janeiro/RJ. 
O conteúdo programático proposto apresentou os seguintes itens: (1) o papel da Arte na produção de conhecimento e na prática pedagógica; (2) Artes Visuais, Cultura e História; (3) tópicos estruturais da evolução das Artes Visuais no Ocidente; (4) as Artes Visuais na cultura de mercado da sociedade contemporânea.

O primeiro dia de aulas (02/04/2008) foi dedicado à apresentação da proposta do curso "As Artes Visuais como campo de conhecimento" e do livro "Roteiro didático da arte na produção do conhecimento", iniciando-se uma reflexão sobre "o que é Arte?". Para tanto, foram consideradas as funções dos objetos e assinaladas a função estética e a atitude estética, como foram propostas por Mukarövský (1998), no livro "Escritos sobre Estética e Semiótica a Arte".

O segundo dia de aulas (09/04) foi utilizado para desenvolver um pouco mais a reflexão sobre a questão proposta nas aulas anteriores, acrescentando-se a ideia de que, diferente do objeto estético que pode ser proposto individualmente, a obra de arte é um fenômeno sócio-político, que depende de legitimação institucional. Além disso, foi dado início ao estudo que explicou a arte como campo de produção do conhecimento.

O terceiro dia de aulas (16/04) serviu para concluir a explicação sobre arte e na produção do conhecimento. Além disso, foi dado início à leitura coletiva do texto "Por que estudar e ensinar arte contemporânea?" (PERASSI, 2006), considerando-se a arte como conteúdo disciplinar e prática pedagógica.

O quarto dia de aulas (23/04) foi ocupado com o restante da leitura, com explicação e com o debate sobre as informações e ideias propostas no texto em estudo. Isso foi feito juntamente com apresentação de imagens de obras de arte e de atividades que ilustraram as explicações oferecidas ao grupo de participantes do curso.

O quinto dia de aulas (30/04) foi dedicado à apresentação de imagens e a explicações sobre as diferenças estruturais na composição visual das obras de arte da Pré-história (30.000 a.C.) ao movimento denominado Impressionismo (séc. XIX), de acordo com períodos e movimentos estilísticos em que foram produzidas.

O sexto dia de aulas (08/05) serviu para apresentar a arte modernista da primeira metade do século XX, descrevendo ainda o processo contraditório que promoveu artisticamente a crítica ao modernismo dentro do próprio período. Pois, isso determinou as bases e estabeleceu as diferenças entre arte modernista e pós-modernista ou contemporânea. 
O sétimo dia (15/05) foi ocupado com a continuidade da apresentação de um panorama ilustrado da arte contemporânea, mostrando-se obras do período iniciado após o ano de 1950, de origem nacional e internacional. Com base nas imagens e nas explicações oferecidas, foram retomadas as ideias desenvolvidas durante o curso, como meio de compor o fechamento do trabalho proposto.

As aulas contaram com a participação de mais de trinta pessoas, houve dias com quase quarenta participantes, cuja maioria foi composta por professores de Arte. Porém, participaram também estudantes de graduação e alguns profissionais de áreas afins, que se interessaram pelo tema. Vinte e oito participantes frequentaram regularmente o curso e receberam o certificado de atividade de extensão emitido pelo Departamento de Projetos de Extensão/UFSC. Parte dos frequentadores, antecipadamente, afirmaram que se interessaram pelo tema e pelas aulas, mas que teriam dificuldades para participar regularmente por necessidade de responderem a outros compromissos acadêmicos ou profissionais. Consideramos qualitativamente que os objetivos foram atingidos, porque os participantes demonstraram interesse e assinalaram que o conteúdo foi acessível e motivador.

\section{CONSIDERAÇÕES FINAIS}

Até aqui foi proposto um breve discurso de apresentação das Artes Visuais como campo de conhecimento, visando à comunicação desse conteúdo e, também, do curso no qual essas ideias foram apresentadas e desenvolvidas, dentro do projeto "Arte na Escola" DAC/UFSC. A existência e a publicação deste texto servem como registro e difusão ampliada dos conteúdos propostos e do curso realizado, com foco na produção artística contemporânea e na estreita relação entre Arte e Conhecimento. Em síntese, Arte é campo de conhecimento porque, ao longo da História, saberes e tecnologias relacionados às atividades artísticas ampliaram o acervo de conhecimentos da humanidade. Há de se considerar que cada obra de arte nos oferece um conhecimento novo sobre algum aspecto do que é percebido ou imaginado. Assim, o fenômeno artístico é campo de produção do conhecimento e, igualmente, é objeto de apreciação, de interesse e de estudo de diversas áreas, sejam essas do próprio campo artístico, do campo filosófico ou do campo científico. 
Agradecemos a oportunidade ao Departamento Artístico Cultural (DAC/UFSC), ao Departamento de Expressão Gráfica (EGR/CCE/UFSC), ao Departamento de Projetos de Extensão/UFSC e, mais especificamente, à coordenação do "Projeto Arte na Escola".

\section{REFERÊNCIAS}

CLICRBS. Especial 11 de setembro: o dia em que o terror venceu. Disponível em:

$<\mathrm{http}$ ://www.clicrbs.com.br/especiais/terrorismo/terror_capa.htm>. Acesso em 10 maio 2010.

DUARTE JR., J. O Sentido dos Sentidos: A Educação (do) Sensível. Curitiba, PR: Criar, 2001.

FABRINI, R. A Arte depois das vanguardas. Campinas, SP: Unicamp, 2002.

FICHER, E. A necessidade da Arte. Rio de Janeiro: Zahar, 1979.

JAKOBSON, R. Lingüística e Comunicação. São Paulo: Cultrix, 1977.

LENARTOVICZ, M. O que é Arte e para quê? In: Civis Mundi. Disponível em:

$<$ http://cmundi.wordpress.com/2009/04/10/o-que-e-arte-e-para-que/>. Acesso em:10 maio 2010.

LUCIE-SMITH, E. Dicionário de Termos de Arte. Lisboa: Dom Quixote, 1990.

MUKARÖVSKÝ, J. Escritos sobre Estética e Semiótica a Arte. Lisboa: Editorial Estampa, 1988.

NEVES, J. Idéias Filosóficas no Barroco Mineiro, Belo Horizonte, Itatiaia, 1986.

OLIVEIRA, A. Arte: uma análise institucional. In: OLIVEIRA et al. Tópicos de Filosofia Geral, São Paulo: Brasiliense, 1998.

PERASSI, R. A institucionalização do fenômeno artístico. In: Anais... $17^{\circ}$ Encontro Nacional ANPAP. Florianópolis, SC: ANPAP-UDESC, 2008.

Por que estudar e ensinar arte contemporânea? Campo Grande: UFMS, 2006.

EDUFMS, 2005.

Roteiro Didático da Arte na Produção do Conhecimento. Campo Grande, MS:

PLATÃO, F.; FIORIN, J. Lições de Texto: Leitura e Redação. São Paulo: Ática, 2006. 